Mini review

\title{
Recent Progress of Electrode Materials for Zinc Bromide Flow Battery
}

Tianyao Jiang ${ }^{1}$, Hang Lin $^{1}$, Qingyang Sun ${ }^{1}$, Guangzhen Zhao ${ }^{1}$, Junyou Shi ${ }^{1,2 *}$

${ }^{1}$ College of Chemical Engineering, Northeastern Electric Power University, Jilin 132012, China

${ }^{2}$ College of Forestry, Beihua University, Jilin 132013, China

*E-mail: bhsjy64@163.com

doi: $10.20964 / 2018.06 .34$

Received: 12 January 2018 / Accepted: 18 March 2018 / Published: 10 May 2018

Saving fossil energy and the widespread application of renewable energy have become important strategies of world government to maintain sustainable development of the society. zinc bromide flow battery can removes the random and intermittent natures of the renewable energy, It becomes one of the most promising technologies with advantages of long cycle life, high energy convention efficiency, flexible system design, deep discharge capability and low cost. In this paper, the focus is on Carbon based material electrode and Carbon nanotube modified electrode.

Keywords: zinc bromine flow battery, Carbon based material electrode, Carbon nanotube modified electrode

\section{$\underline{\text { FULL TEXT }}$}

(C) 2018 The Authors. Published by ESG (www.electrochemsci.org). This article is an open access article distributed under the terms and conditions of the Creative Commons Attribution license (http://creativecommons.org/licenses/by/4.0/). 